\title{
PCR Based Detection and Phylogenetic Analysis of Fowl Adenovirus Strains Isolated from 2019 Epidemic from Punjab and Sindh, Pakistan
}

\author{
Nadeem Sharif ${ }^{1}$, Muhammad Danish Mehmood ${ }^{2 *}$, Syed Zeeshan Haider Naqvi ${ }^{1}$, \\ Huma Anwar ul-Haq², Syed Shoaib Ahmed', Muhammad Usman Ghani'2, \\ Muhammad Shoaib3 ${ }^{3}$ Mubashir Hussain4 \\ ${ }^{1}$ Institute of Molecular Biology and Biotechnology, University of Lahore, Lahore, Pakistan \\ ${ }^{2}$ Ottoman Pharma (Immuno Division), Lahore, Pakistan \\ ${ }^{3}$ College of Veterinary Sciences, FSH \& VS, Peshawar, Pakistan \\ ${ }^{4}$ Kohat University of Science \& Technology, Kohat, Pakistan \\ Email: nadeemsharif291@gmail.com, *drdanishmehmood@gmail.com, Zeeshan.haider@imbb.uol.edu.pk, \\ huma.anwar16@gmail.com, Shoaib.ahmed@imbb.uol.edu.pk, u.kashmiri@gmail.com,Dr_shoaibpk@yahoo.com
}

How to cite this paper: Sharif, N., Mehmood, M.D., Naqvi, S.Z.H., ul-Haq, H.A., Ahmed, S.S., Ghani, M.U., Shoaib, M. and Hussain, M. (2020) PCR Based Detection and Phylogenetic Analysis of Fowl Adenovirus Strains Isolated from 2019 Epidemic from Punjab and Sindh, Pakistan. American Journal of Molecular Biology, 10, 246-258. https://doi.org/10.4236/ajmb.2020.103016

Received: April 29, 2020

Accepted: July 18, 2020

Published: July 21, 2020

Copyright () 2020 by author(s) and Scientific Research Publishing Inc. This work is licensed under the Creative Commons Attribution-NonCommercial International License (CC BY-NC 4.0). http://creativecommons.org/licenses/by-nc/4.0/ (c) (i) (8) Open Access

\begin{abstract}
Hydro-Pericardium Hepatitis ( $\mathrm{HPH})$ is an emerging infectious disease of commercial poultry, caused by different serotypes of Fowl Adeno Virus. The vertical transmission of the virus into the progeny may results in devastating damage, causing huge economic losses to its farmers. In present study, molecular typing is performed on basis of partially conserved hexon gene sequences, using a unique set of primers having common reverse oligo for simultaneous detection of FAdV1, FAdV-4 and FAdV-11. A total of 14 fowl adeno virus strains were isolated from 100 suspected adeno virus liver samples, collected from different districts in Pakistan, between 2018 and 2019. FASTA's sequence alignment and phylogenetic analysis revealed that out of the 14, one isolate which belonged to group A showed $27 \%$ similarity with FAdV-1, while three isolates showed $99 \%$, 95\% \& $45 \%$ similarity to FAdV-4 (Group C). Whereas, ten isolates showed more than 99\% similarity to FAdV-11 (Group D). The serotypes FAdV1, FAdV-4 and FAdV-11 are prevailing in the breeder and broilers. These results hold great importance in rapid, reliable and simultaneous detection of the three FAdV serotypes. Therefore, fowl adeno virus vaccine production for commercial poultry shall be according to the prevalent field serotypes.
\end{abstract}

\section{Keywords}

Hydro-Pericardium Hepatitis (HPH), Hexon Gene, Polymerase Chain Reaction, Phylogenetic Analysis, Sanger's Sequence 


\section{Introduction}

Infectious hepatitis is a common problem of modern commercial poultry farming in Pakistan. It is caused by a variety of toxic and infectious agents, which include feed toxicity, bacteria and mostly harbored by influenza and adeno virus subtypes. Fowl adeno virus subtypes are the most common cause of Hydro-pericardium Syndrome (HPS), Hydro-pericardium Hepatopathy Syndrome (HHS), Hydro-pericardium Hepatitis Syndrome (HHS), Inclusion Body Hepatitis (IBH) and Egg Drop Syndrome (EDS) [1] [2].

Fowl Adenovirus (FAdV) belongs to the family Adenoviridae and genus Aviadenovirus divided into 5 species (FAdV-A to FAdV-E) based on their restriction enzyme digestion pattern and into 12 serotypes on the base of cross neutralization test [3] [4]. It has a double-stranded DNA genome of approximately 43 to $46 \mathrm{~kb}$, which encodes 10 major structural and 11 non-structural proteins, including E1A, E1B, DBP, ADP, E4, 52/55 K, pIVaII, pol, EP, $33 \mathrm{~K}$, and $100 \mathrm{~K}$ [5] [6]. Hexon gene is the major protein, which controls the variability of FADV, and has the sequence of $2800 \mathrm{bp}$ to $2900 \mathrm{bp}$ with the weight of 103 Kda resulting diversity of 12 serotypes. Its mortality rate ranges from $30 \%$ to $70 \%$ in broilers and significant drop in egg production in breeders and layers [7] [8] [9]. FAdV spread both horizontally by faeces and vertically in the mean of progeny.

In 1987 the disease was first identified at Angara Goth near Karachi in Pakistan. HPS and IBH are contagious viral problems of breeders and fast-growing broilers are being infected particularly at young age. The disease is characterized by off feed and water, respiratory rales, pasting of whitish colored diarrhea on vent and morbidity up to $100 \%$. Fowl adeno virus infections are conventionally diagnosed by sign symptom, appearance of typical lesions, virus isolation on in vitro tissue culture and chicken embryonated eggs. Agar gel precipitation test (AGPT) is still being used for the detection of fowl adeno virus antibodies in exposed birds, whereas, indirect enzyme linked immunosorbent assay (ELISA) and virus neutralization test (VNT) are other reliable tools for detecting type-specific antibodies and groups. Due to the high diversity in the FADV strains, diagnosis of FADV strains has become very expensive and time-consuming process in $\mathrm{Pa}$ kistan. The attempt was made with the aim to produce a novel technique for the rapid identification of three different FADV serotypes in a single PCR reaction using common reverse oligo. This would help in saving time and cost for rapid screening of commercial breeder and layer flocks in future.

\section{Materials and Methods}

\subsection{Sample Size}

The sample size was calculated by using the formula of Kish \& Lisle states that [10]

$$
n=Z^{2} P(1-P) / d^{2}
$$


Where, $z=$ Score for $95 \%$ confidence interval = 1.96 ;

$P=$ Prevalence (To estimate the proportion of morbidity with HPS \& IBH);

$d=$ Sampling error that could be tolerate $=5 \%$;

$1 P=$ Probability.

\subsection{Sample Collection}

Using statistical formula $\left(n=Z^{2} P(1-P) / d^{2}\right) 30 \mathrm{~g}$ of liver were collected in sterile polythene labelled bag from each of 100 suspected Adenovirus infected broilers/breeder flocks reported from all across Pakistan and transported to Ottoman Pharma (Immuno Division) where it was stored at $-20^{\circ} \mathrm{C}$ till further use. The detailed history of these collected isolates was described in Table 1.

\subsection{Virus Isolation}

$10 \%$ of liver homogenate was prepared in $0.9 \%$ Normal saline (Zeesol Pharma-Pakistan) solution in an electric homogenizer (B. Braun-Germany). The suspension was centrifuged at $2^{\circ} \mathrm{C}$ and $3000 \mathrm{~g}$ for 2 minutes and the supernatant was collected for filtration. The clear supernatant was then passed through a 0.2 $\mu \mathrm{m}$ size filter (Sartorius-Germany) and admixed with $1 \%$ of pen strep (Gibco-USA) in the final concentration.

Table 1. History details of isolates recovered from different flock all across Pakistan.

\begin{tabular}{|c|c|c|c|c|c|c|}
\hline Sr. No. & Sample Name & Source & Flock type & Post Mortem lesions & Morbidity & Mortality \\
\hline 1. & D14.EDS/CHICKEN/OP.PK/2019 & Rawalpindi & Broiler & Digestive & $8 \%$ & $25 \%$ \\
\hline 2. & D13.HPS/CHICKEN/OP.PK/2019 & Gujarat & Breeder & Respiratory & $5 \%$ & $20 \%$ \\
\hline 3. & D12.HPS/CHICKEN/OP.PK/2019 & Gujranwala & Broiler & Digestive & $15 \%$ & $40 \%$ \\
\hline 4. & D11.HPS/CHICKEN/OP.PK/2019 & Lahore & Broiler & Digestive & $6 \%$ & $22 \%$ \\
\hline 5. & D10.IBH/CHICKEN/OP.PK/2019 & Karachi & Broiler & Digestive & $10 \%$ & $50 \%$ \\
\hline 6. & D09.IBH/CHICKEN/OP.PK/2019 & Pattoki & Broiler & Digestive & $1 \%$ & $18 \%$ \\
\hline 7. & D08.IBH/CHICKEN/OP.PK/2019 & Sheikhupura & Breeder & Respiratory & $5 \%$ & $30 \%$ \\
\hline 9. & D06.IBH/CHICKEN/OP.PK/2019 & Gujranwala & Breeder & Respiratory & $5 \%$ & $30 \%$ \\
\hline 10. & D05.IBH/CHICKEN/OP.PK/2019 & Gujranwala & Broiler & Digestive & $7 \%$ & $22 \%$ \\
\hline 11. & D04.IBH/CHICKEN/OP.PK/2019 & Lahore & Breeder & Respiratory & $10 \%$ & $38 \%$ \\
\hline 12. & D03.IBH/CHICKEN/OP.PK/2019 & Karachi & Broiler & Digestive & $10 \%$ & $35 \%$ \\
\hline 13. & D02.IBH/CHICKEN/OP.PK/2019 & Rawalpindi & Broiler & Digestive & $5 \%$ & $30 \%$ \\
\hline 14. & D01.IBH/CHICKEN/OP.PK/2019 & Lahore & Broiler & Digestive & $2 \%$ & $25 \%$ \\
\hline
\end{tabular}

${ }^{\star}$ Digestive signs—loose dropping, whitish Pasting or vent, Mucoid droppings due to excess bile acids; ${ }^{\star}$ Respiratory signs—gasping, sneezing, pulmonary edema, lethargy huddling. 


\subsection{Virus Preparation on Cell Lines}

1.5\% solution of Dulbecco's Modified Essential Medium (DMEM) (Gibco-USA) was prepared in doubled distilled water. Vero cell line was retrieved from liquid nitrogen and one million cells were added to the T-25 tissue culture flask (SPL-Germany) supplanted with 10\% Fetal Calf Serum (FCS) (Gibco-USA). Antibiotic combination of penicillin and streptomycin was added at $1 \%$ concentration. The cells containing roux flask was incubated at $37^{\circ} \mathrm{C}$ for 48 hours in the presence of $5 \% \mathrm{CO}_{2}$.

\subsection{Virus Isolation and Propagation}

T-25 tissue culture flask containing Vero cell line confluent monolayer was infected with $0.5 \mathrm{ml}$ of filtrate liver homogenate. $2 \%$ FCS was added in the flask and incubated at $37^{\circ} \mathrm{C}$ for $48-72$ hours. The monolayer was observed for cytopathic effect after every 12 hours and results were recorded.

\subsection{DNA Extraction}

The flask containing the Infected Vero cell line was freeze at $-40^{\circ} \mathrm{C}$ for half an hour and then incubated at $37^{\circ} \mathrm{C}$ in a water bath for 10 minutes. The process was repeated three times and the cell media suspension was centrifuged at $3000 \mathrm{~g}$ for five minutes. Sediment was decanted and the supernatant was collected in the sterile tube that is subjected to DNA extraction. The supernatant was collected and modified as described by QIAGEN-Germany.

\subsection{Oligos Designing}

Partial CDS sequences of the Hexon gene of all 12 FADV serotypes were cited from the Gene bank database with the help of their accession numbers (AF339914 to AF339925). All the 12 sequences were aligned on the bioinformatics tool (Clustal Omega 1.2) for multiple sequence alignment and similarity. Serotype 1, 4 and 11 showed the maximum similarity index of more than $75 \%$. So, these three sequences were separately aligned again to find out the conserved region for designing of highly sensitive primers. Common reverse primers were designed from lower strand exonic part of the L5 loop region of the Hexon gene. Similarly, other 3 forward primers were designed from the upper exonic region of Hexon gene. Serial cloner 1.3 was used to run the PCR in silico to check the efficacy of primers before order and further their Amplicon sizes were estimated as mention in Table 2.

Table 2. Primer sequences, amplicon size and melting temperature in accordance with genotype.

\begin{tabular}{|c|c|c|c|c|c|}
\hline SR. & Primer & Sequences & Amplicon Size & TM Value $\left({ }^{\circ} \mathrm{C}\right)$ & Genotype \\
\hline \multirow{2}{*}{1} & Forward & CAGCGGGCGTGAAGCA & \multirow{2}{*}{$1219 \mathrm{bp}$} & 55 & \multirow{2}{*}{ Strain 1} \\
\hline & Reverse & TAGTGATGACGGGACATCAT & & 56 & \\
\hline \multirow{2}{*}{2} & Forward & CGAGGATTACGACGATTA & \multirow{2}{*}{$900 \mathrm{bp}$} & 52 & \multirow{2}{*}{ Strain 4} \\
\hline & Reverse & TAGTGATGACGGGACATCAT & & 56 & \\
\hline \multirow{2}{*}{3} & Forward & CGGCGCCCGGACAAAA & \multirow{2}{*}{899 bp } & 55 & \multirow{2}{*}{ Strain 11} \\
\hline & Reverse & TAGTGATGACGGGACATCAT & & 56 & \\
\hline
\end{tabular}




\subsection{Polymerase Chain Reaction (PCR)}

Three positive sense primers along with common negative primers were used in the reaction of multiplex PCR against 1, 4 and 11 strain. One microliter of the forward primer of each serotype along with one microliter of common reverse primer for all three serotypes was added into the $100 \mu \mathrm{l}$ PCR reaction tube. Other ingredients of the recipe include $12 \mu \mathrm{l}$ master mix, $7 \mu$ injection water, and 4 $\mu \mathrm{l}$ of each processed DNA sample. The PCR programmed was set at initial denaturation at $95^{\circ} \mathrm{C}$ for five minutes followed by 45 cycles of denaturation at $95^{\circ} \mathrm{C}$ for $45 \mathrm{Sec}$, annealing at $55^{\circ} \mathrm{C}$ for $45 \mathrm{Sec}$ and extension at $72^{\circ} \mathrm{C}$ for the $90 \mathrm{Sec}$. The final extension was done at $72^{\circ} \mathrm{C}$ for 10 minutes. $2 \%$ agarose gel (Bio world) was prepared following method recommended by Shahzad [11].

\subsection{Sanger's Sequencing}

$50 \mu \mathrm{l}$ of PCR product (Amplicon) for each liver sample was organized according to the Performa and submitted in the advance bioscience international for dispatch to Korea. The sequencing was performed by the Sanger method.

\subsection{Phylogenetic Analysis}

After sequencing, all the 14 sequences were annotated (NCBI Annotation v5) to find out their CDS regions. All our sequences were directly submitted to the NCBI database. Alignment and phylogenetic reconstructions were performed using the function "build" of ETE3 v3.1.1 as implemented on the GenomeNet (https://www.genome.jp/tools/ete/) [12]. Alignment was performed with MAFFT v6.861b with the default options [13]. The tree was constructed using Fast Tree v2.1.8 with default parameters. Values at nodes are SH-like local support to find out the likelihood between all the strains.

\section{Results}

On the request of farmers, different broiler/breeder farms were visited in the Punjab province \& Pakistan. The Adenovirus suspected dead birds showed whitish vent pastings and most of them were found in dorsal recumbency. On postmortem clear straw color fluid varies from one $\mathrm{ml}$ to five $\mathrm{ml}$ in few birds was recorded but the liver was enlarged showing uniformly distributed petechial hemorrhages throughout each lobe. The liver was highly fragile and pale in color with longitudinal and vertical whitish streaks as showed in Figure 1. There was mild splenomegaly, nephritis, and severe hepatitis also recorded in some birds.

Vero cell line confluent monolayer showed vacuolation and detachment of cells after 72 hours of infection under 20× magnification lens of inverted microscope (Nikon-Japan) as depicted in Figure 2. The viral harvest showed more than $1 \times 10^{6.2}$ tissue culture infective dose ${ }_{50}$. Polymerase chain reaction for each cultivated samples showed variable amplicon size in gel electrophoresis. Fowl Adeno type 1, type 4 and type 11 showed amplicon size of 1216, 900 and $900 \mathrm{bp}$ respectively as showed in Table 3. 
Table 3. FAdV group allocation after successful cultivation on cell line and PCR based confirmation.

\begin{tabular}{|c|c|c|c|c|c|c|}
\hline Sr. No. & Source & Flock Type & $\begin{array}{l}\text { Sample Showing } \\
\text { Typical Factors }\end{array}$ & $\begin{array}{c}\text { Growth on } \\
\text { Vero Cell Lines }\end{array}$ & $\begin{array}{c}\text { PCR Results } \\
\text { (Amplicon size bp) }\end{array}$ & $\begin{array}{l}\text { Sequencing } \\
\text { Results }\end{array}$ \\
\hline 1. & Rawalpindi & Broiler & EDS & YES & 1216 & Group A \\
\hline 2. & Gujarat & Breeder & HPS & YES & 900 & Group C \\
\hline 3. & Gujranwala & Broiler & HPS & YES & 900 & Group C \\
\hline 4. & Lahore & Broiler & HPS & YES & 900 & Group C \\
\hline 5. & Karachi & Broiler & IBH & YES & 900 & Group D \\
\hline 6. & Pattoki & Broiler & IBH & YES & 900 & Group D \\
\hline 7. & Sheikhupura & Breeder & IBH & YES & 900 & Group D \\
\hline 8. & Sahiwal & Broiler & IBH & YES & 900 & Group D \\
\hline 9. & Gujranwala & Breeder & IBH & YES & 900 & Group D \\
\hline 10. & Gujranwala & Broiler & IBH & YES & 900 & Group D \\
\hline 11. & Lahore & Breeder & IBH & YES & 900 & Group D \\
\hline 12. & Karachi & Broiler & IBH & YES & 900 & Group D \\
\hline 13. & Rawalpindi & Broiler & IBH & YES & 900 & Group D \\
\hline 14. & Lahore & Broiler & IBH & YES & 900 & Group D \\
\hline
\end{tabular}

${ }^{\star}$ HPS (Hydro pericardium syndrome), ${ }^{\star}$ IBH (Inclusion body hepatitis).
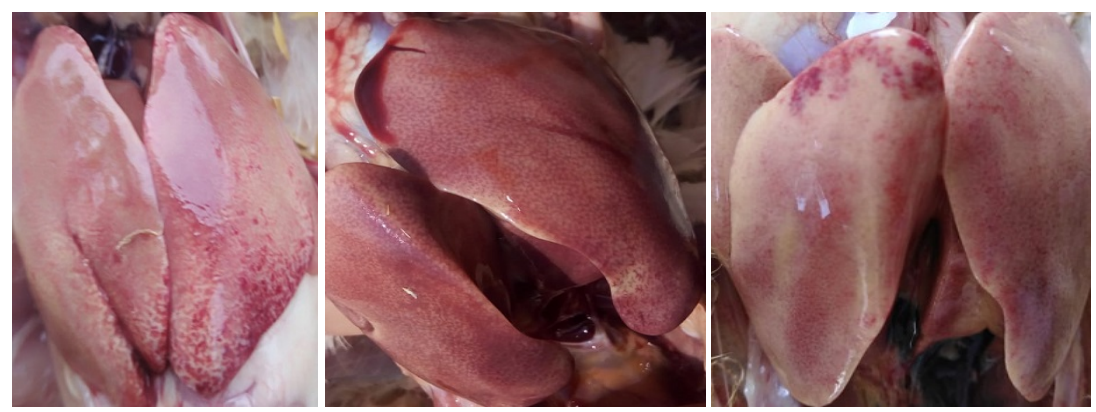

Figure 1. Pathognomonic lesions of IBH.
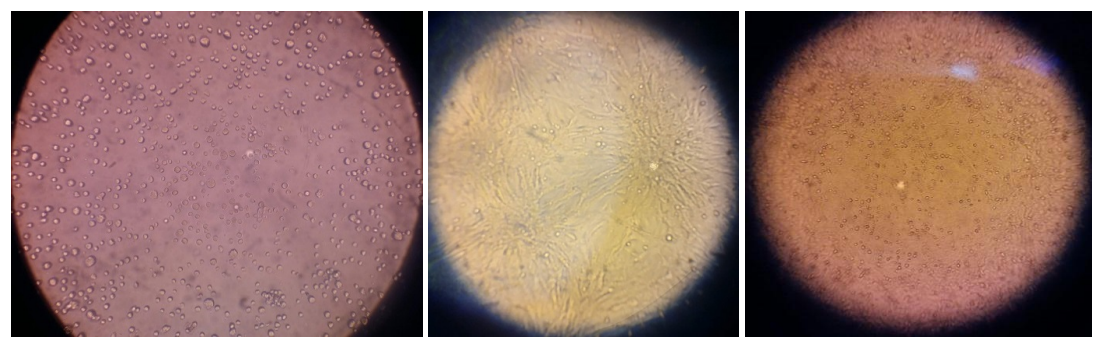

Figure 2. Normal and FAdV infected Vero cell line.

The sequencing of each PCR product revealed that three different types of FAdV were present in the infectious material. The dominant type was FAdV-11 (75\%) followed by FAdV-4 (60\%) and FAdV-1 (10\%). The FASTA sequences alignment with the partial coding DNA sequences (CDS) regions taken from local and Austrian gene banks showed partial homology with the few samples whereas, the non-homologous pattern for most of the DNA sequences. $90 \%$ of samples were declared positive based on sign symptoms whereas, $70 \%$ were reported in PCR amplification as depicted in Figure 3. 


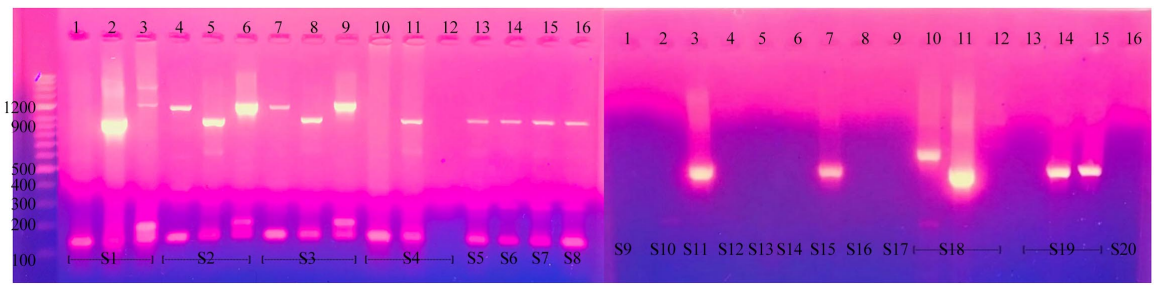

Figure 3. Gel electrophoresis.

The chromatogram for hexon gene of fowl adeno virus nucleotide specificity in sequencing is shown in Figures 4-6, whereas, similarity index of isolates with reference fowl adeno viruses by NCBI blast along with generated accession number has been depicted in Table 4.

\section{Hexon Gene sequence of FAdV-1 (Group A):}

Locus: D14.EDS/CHICKEN/OP.PK/2019 852 bp DNA linear VRL 20-DEC-2019

Organism: Fowl Aviadenovirus A

1 caaccanatc caaccgagaa ggccagaggc tccagatcag gttttacccg acgcagaccg 61 acgacacgcc caacagttac cgcgtgcggt acagcttaaa cgtgggtgac agttgggttc

121 tggacatggg agccacctac ttcgacatca agggcgtcct agacagagga ccttctttta

181 aaccgtatgg aggaaccgca tacaatcccc tcgcgccccg cgaagccttt ttcaacaatt 241 gggttgacac agaggcgagc aagaccgtca tcacgggtca gatgacaact ccctacgaaa 301 acgtccaggg cgctaaagac aagactgccg cgatcgtcgc cgctctttca ggggtttatc 361 ccgatcccaa tatcggtacc gccatcagcg agatgggcgc cttaaacgcg acgtcggcag 421 cccaagtcgg attggetgcc cgattcgcga aagtatcgag cgataacacg cgtctagcct 481 acggagccta cgttaaaccg ctcaagaacg acggttctca atcgattaac cccactcctt 541 actgggtcat ggacagcaac gccacaaact atctcggagt catgggagtc gaagacttta 601 gcgcctcgct aacctatccc gatacgctcc ttattccccc gccaaccgaa tactcagaag 661 tgaataccgg cgtcatgaag gcaaacaggc cgaattacat cggatttagg gacaatttta 721 tcaacctgct ctatcatgat acgggtgtgt gctcgggtac tctgaattcg gagcgttcgg 781 gtatgaacgt cgtcgtcgag ctccaggaca gaaacacgga acttagttac cagtacatgt 841 tagccgatat ga

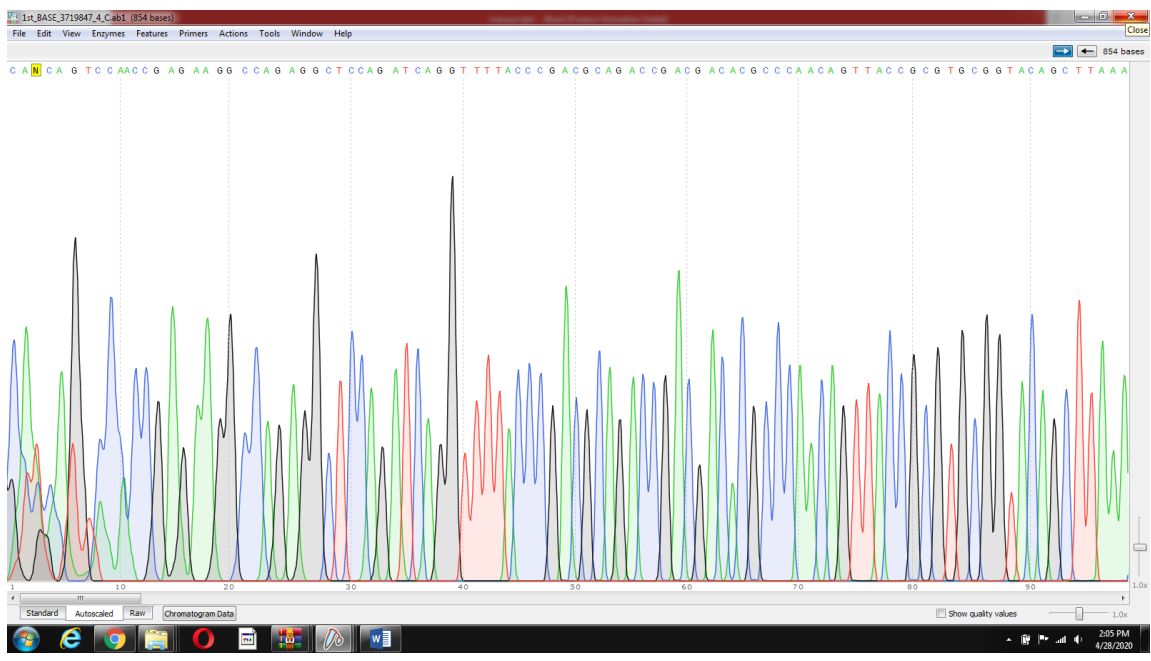

Figure 4. Chromatogram of FAdV-1 (Group A) nucleotides specificity in sequencing. 


\section{Hexon Gene sequence of FAdV-4 (Group C):}

Locus: D11.HPS/CHICKEN/OP.PK/2019 874 bp DNA linear VRL 20-DEC-2019

Organism: Fowl Aviadenovirus $\mathrm{C}$

1 cggcacccta acccaccgag gaaggccaga ggctccagat caggttttac ccgacgcaga 61 ccgacgacac gcccaacagt taccgcgtgc ggtacagctt aaacgtgggt gacagttggg 121 ttctggacat gggagccacc tacttcgaca tcaagggcgt cctagacaga ggaccttctt 181 ttaaaccgta tggaggaacc gcatacaatc ccctcgcgec ccgcgaagcc tttttcaaca 241 attgggttga cacagaggcg agcaagaccg tcatcacggg tcagatgaca actccctacg 301 aaaacgtcca gggcgctaaa gacaagactg ccgcgatcgt cgccgctctt tcaggggttt 361 atccegatcc caatatcggt accgccatca gegagatggg cgccttaaac gcgacgtcgg 421 cagcccaagt cggattggct geccgattcg cgaaagtatc gagcgataac acgcgtctag 481 cctacggagc ctacgttaaa ccgctcaaga acgacggttc tcaatcgatt aaccccactc 541 cttactgggt catggacagc aacgccacaa actatctcgg agtcatggga gtcgaagact 601 ttagcgcctc gctaacctat cccgatacgc tccttattcc cccgccaacc gaatactcag 661 aagtgaatac cggcgtcatg aaggcaaaca ggccgaatta catcggattt agggacaatt 721 ttatcaacct gctctatcat gatacgggtg tgtgctcggg tactctgaat tcggagcgtt 781 cgggtatgaa cgtcgtcgtc gagctccagg acagaaacac ggaacttagt taccagtaca 841 tgttagccga tatgatgtcc ggtccttcac taaa

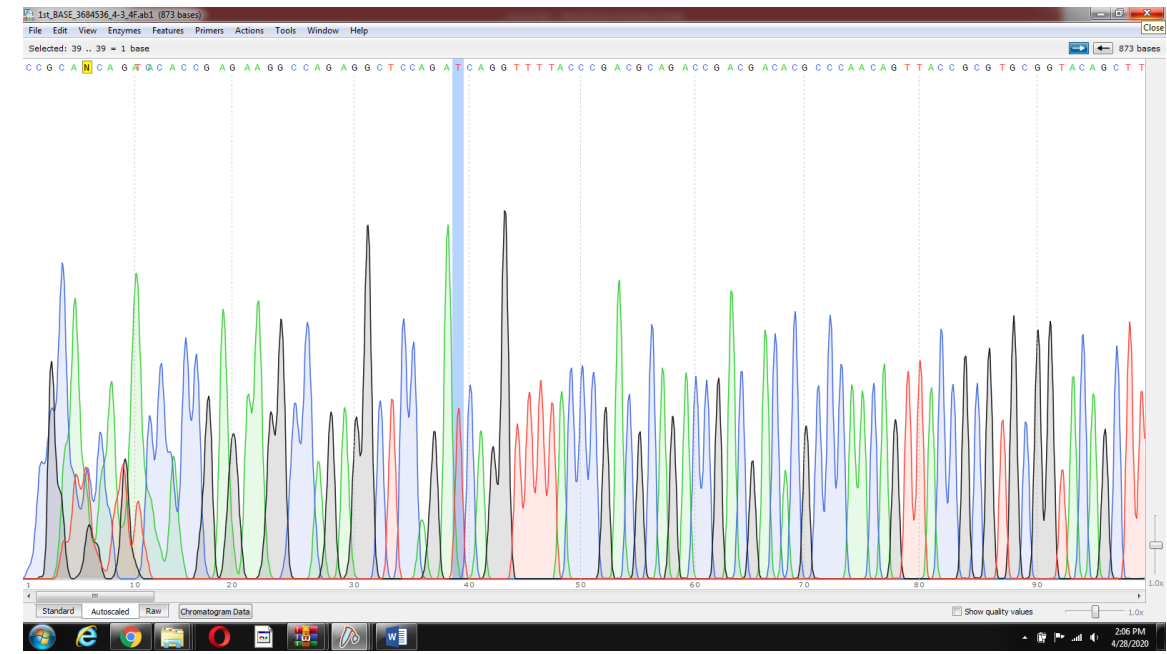

Figure 5. Chromatogram of FAdV-4 (Group C) nucleotides specificity in sequencing.

\section{Hexon Gene sequence of FAdV-11 (Group D):}

Locus: D1.IBH/CHICKEN/OP.PK/2019 1099 bp DNA linear VRL 20-DEC-2019

Organism: Fowl Aviadenovirus D

1 ctgaaggttc catatccagg ttccgcagaa atacttcgct attaaaaatc tgctgctgtt

61 gcceggcacc tacacctacg agtgggtgct cagaaaggac cccaacatga ttctgcagtc 121 cagtttaggc aatgatctga gagccgacgg agcttcgatc gtgtactctg aagtaaacct 181 aatggctaac ttcatgccca tggatcacaa tacaagcaat cagcttgagc tcatgctcag 241 aaacgccact aacgatcaaa cattcgcaga ctatctaggt gccaagaatg cgttgtatca 301 agtacccgcg ggctccacgg cacttaccat taacattcca gctcgcacct gggagggtat 361 gcgtggttgg tcttttaccc gtgtcaaagc ttcagaaact ccgcagatag gagcccaata 
421 tgacgttaac ttcaagtatt cgggaacaat tccatactct gacggcacct tctatttgac 481 ccacacgttc aggaacatga gcgtgctatt cgacacgtcc atcaattggc ccgggaacga 541 ccggttgcta gcacccaacc tgttcgaaat caagcgcaat gtgggcatcg attcagaagg 601 gttcacgatg tcccaatgtg acattactaa agattggtac ctgatccaaa tggccaccaa 661 ctacaactac gtatttaacg gataccggtt ctggcccgac agacaatatt tccattatga 721 cttcctccgg aatttcgacc ccatgacccg gcagggccet aattccaag accaaacatt 781 gttcgattta accgaatacg aacccacgat acccatctct ccaggatcta tgcaaacggg 841 gcaagacgct atccgtaata attcaggcta cacagctccg cgcagttggc ccgtatacag 901 cgctcagcag gatgagtctt ggccegccaa ttggccttat ccgctcatcg ggagcgaatc 961 catcctgccg tcccanatgg ttaactacaa gaagttcttg ggcgacaact atctatggac 1021 cggttccgtt cagttccaat tcctggtnat ggggtgaacg gaccgattcc gcnaaaatcc 1081 tttgaaccta aggattccc

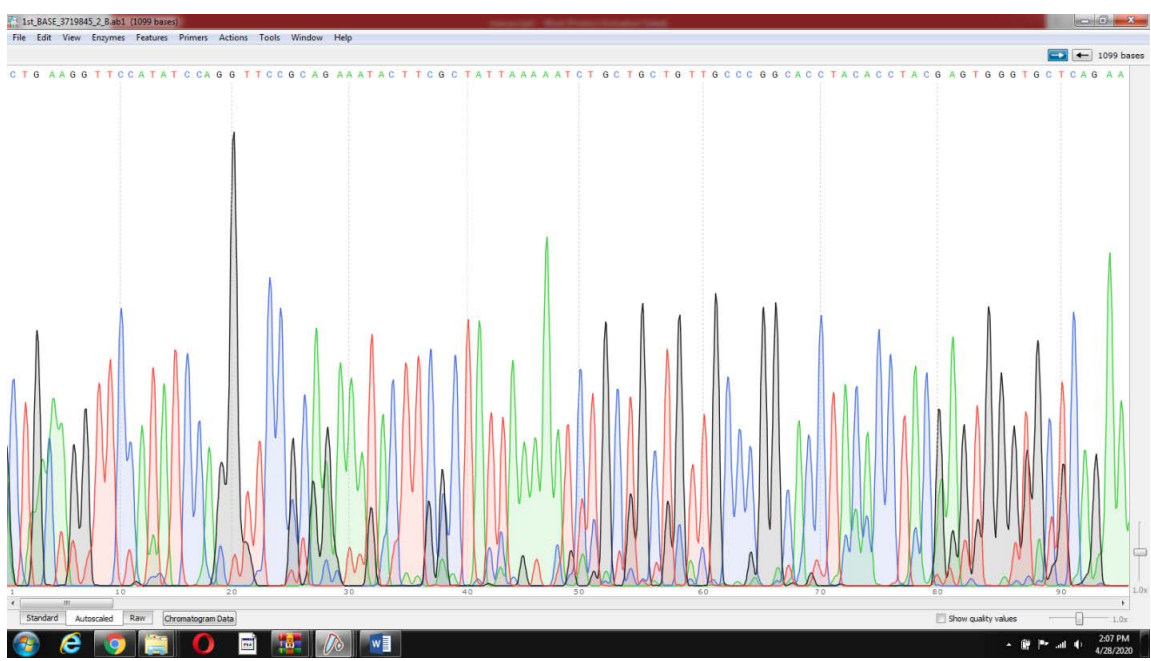

Figure 6. Chromatogram of FAdV-11 (Group D) nucleotides specificity in sequencing.

Table 4. NCBI accession number, similarity index and genotype by using blast.

\begin{tabular}{ccccc}
\hline Isolate Accession No. & Gen Bank Accession No. & Percentage Similarity\% & Serotype Groups & Genotype \\
\hline MN861105 & MK575871.1 & $27 \%$ & Group A & FAdV 1 \\
MN861104 & MK572871.1 & $45 \%$ & Group C & FAdV 4 \\
MN861103 & MH151202.1 & $99 \%$ & Group C & FAdV 4 \\
MN861102 & MK875248.1 & $95 \%$ & Group C & FAdV 4 \\
MN861101 & MH379252.1 & Group D & FAdV 11 \\
MN861100 & MG029114.1 & $99 \%$ & Group D & FAdV 11 \\
MN861099 & MH379254.1 & $99 \%$ & Group D & FAdV 11 \\
MN861098 & MH379251.1 & Group D & FAdV 11 \\
MN861097 & MK572871.1 & $98 \%$ & Group D & FAdV 11 \\
MN861096 & MH379251.1 & $98 \%$ & Group D & FAdV 11 \\
MN861095 & MH379252.1 & $99 \%$ & Group D & FAdV 11 \\
MN861094 & MK572871.1 & $99 \%$ & Group D & FAdV 11 \\
MN861093 & MK572871.1 & $99 \%$ & Group D & FAdV 11 \\
MN861092 & MK572871.1 & $98 \%$ & Group D & FAdV 11 \\
\hline
\end{tabular}

*Prevalence of FAdV (FAdV-1 7\%, FAdV-4 21\%, and FAdV-11 78\%). 
The L5 loop region of the Hexone gene sequences of isolates from Punjab and Karachi regions were submitted in GenBank with their accessions numbers (MN861092 to MN861105) respectively. The isolate number MN861105 showed $27 \%$ similarity with the accession number MK575871 as compare to the isolate numbers MN861103 have 99\% sequence similarity to the accession numbers MH151202. Similarly, three isolates MN861099, MN861098 and MN861094 have 98\% sequence similarity to accession number MH379254, MH379251 and MK572871. Based on sequencing similarity percentage to the FAVs reference strains and phylogenetic analysis revealed that $71 \%$ of isolates were FAV-11 followed by FAV-4 (21\%) and FAV-1 (7\%).

\section{Discussion}

The sequencing of FAdV PCR products obtained from a unique set of designed primers confirmed the presence of three fowl Adenovirus isolates from the different geographical areas of Pakistan. The isolates were cultivated on the Vero cell line and confirmed the progeny through PCR using three different sets of primers. The sequencing of these products confirmed FAdV1, FAdV4, and FadV11, whereas other serotypes such as FAdV-2, FAdV-6, and FAdV-12 had been reported for its circulation in the environment [14]. However, in the current study, only three subtypes have been confirmed in which FAdV-11 is the dominant strain that has to be considered the major factor causes huge losses in the recent outbreaks.

The results of the current study corroborate with the findings of Deherdt who reported that HHS (Hepatitis Hydro pericardium syndrome) cases linked to FAdV-4 whereas IBH (Inclusion Body Hepatitis) cases are associated with FAdV-8 and FAdV-11. FAdV-1 has also been isolated from many farms in which birds showed remarkable gizzard atrophy [15] [16] [17]. Concurrent infection of FAdV with multiple types is common [18].

Pathological findings such as Hepatitis, Hydro-pericardium Syndrome, Inclusion Body Hepatitis, and severe pleural ascites along with fibrinous air vasculitis were observed in almost every case we studied. Several birds from different farms were recorded positive for chicken anemia viruses and infectious bursal disease as well. Five farms were also infected with Newcastle disease virus; sever tracheitis and inflammation of the upper respiratory tract is very well exploding on post mortem. De-Herat reported that chicken anemia virus/infectious bursal disease virus are predisposing and supportive factors for augmentation of inclusion body Hepatitis [15].

The results of the analysis indicated that all the isolates belong to the family adenoviridae and their sequences showed a high resemblance to the sequences of loop L1 of Adenovirus strains recovered from commercial and wild birds. A total of 63 FAdV references and reported FASTA sequences of 14 FAdV reference and reported strains were downloaded from the GenBank database including 5 Pakistanis and 4 ATCC cultures. According to nucleotide sequence alignment and construction of phylogenetic tree one strain was categorized in species FAdV-A; 
three strains were grouped into FAdV-C; and the remaining 12 strains were placed into FAdV-D. The Hexone gene is the longest gene of the Adenovirus genome responsible for antigenic and immunogenic properties [19] [20]. Phylogenetic tree structure consists of three main branches representing FAdV Spp as FAdV-A, FAdV-C, and FAdV-D. The first clad originated from branch showed the $27 \%$ similarity of isolate MN861105 with the reference strain MK575871, whereas isolate MN861093, MN861094 were showing 45\% and 99\% similarity with the MK572871 and MH151202. When the $2^{\text {nd }}$ clad wad observed our fourth strain MN861096 was showing a 95\% similarity index with the MK875248 of reference strains. In the third clad of our phylogenetic tree our 10 sequences MN861095, MN861097, MN861098, MN861099, MN861100, MN861101, MN861102, MN861103, MN861104, and MN861105 were showing 99\% and 98\% ratio with the NCBI reference strains MH379252, MG029114, MH379254, MH379251, MK572871, MH379251, MH379252, MK572871, MK572871, and MK572871 respectively as mentioned in Figure 7.

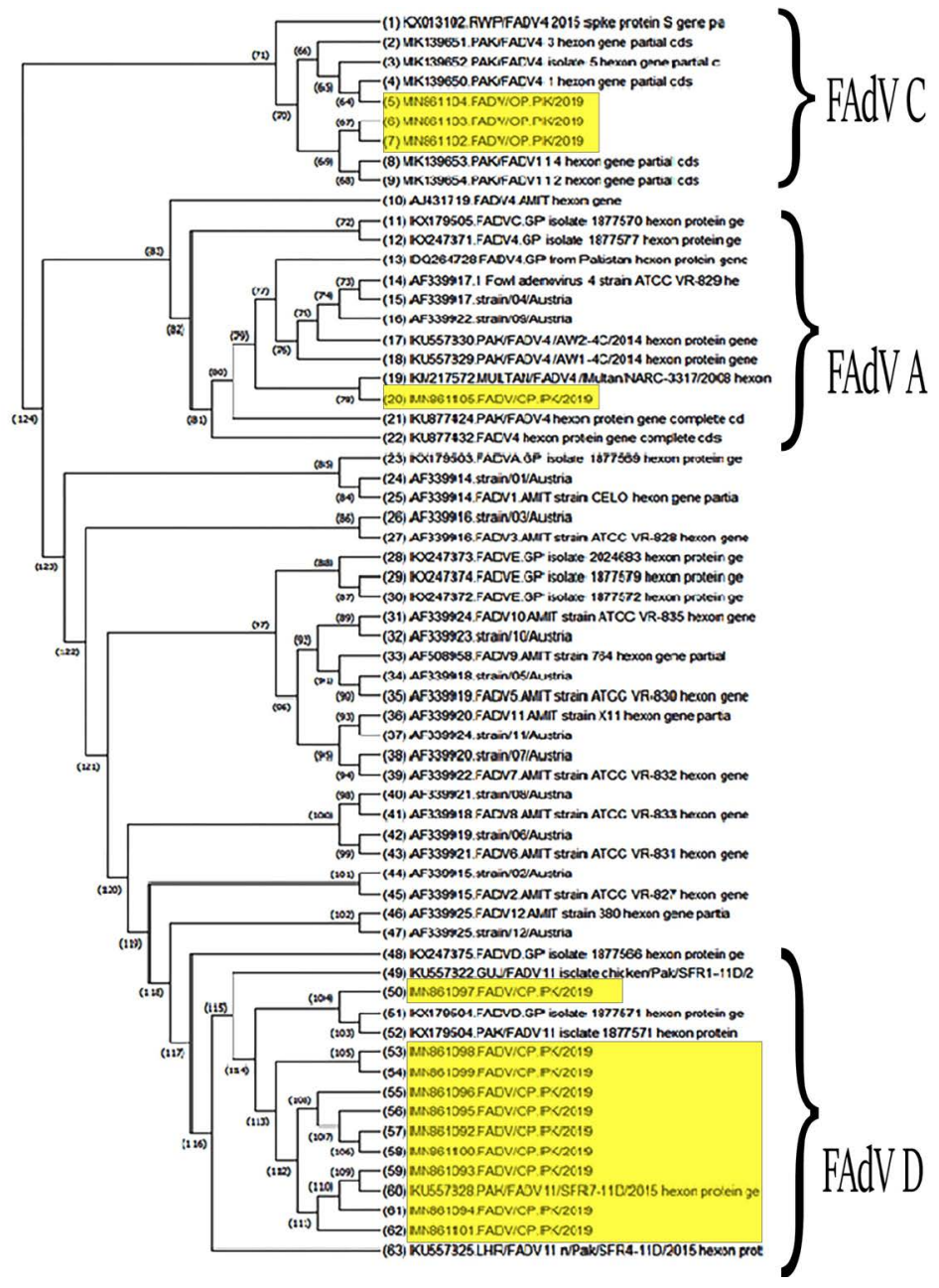

Figure 7. Phylogenic analysis of the indeginous fowl adeno virus strains based on partial coding DNA sequences of hexon gene deanalysed indeginous strain are highlighted. 1 strain belongs to specie A/FAdV-1, 3 isolates belong to specie C/FAdV-4 and 10 strains belong to specie D/FAdV-11. 
Highest prevalence of FAdV-11 (71\%) is followed by FAdV-4 (21\%) and FAdV-1 (7\%). Our results are similar to results from Toro where Adenovirus isolates frequently belong to the spp Aviadenovirus D group [21]. The serotype of FAdV-1 was least frequent (8\%). Moreover, FAdV serotypes FAdV-3, FAdV-6, FAdV-9, and FAdV-10 have not been reported in Poland. The difference in the L1 sequence of the Hexon gene of FAdV within the clad and even in group may be due to the mutation in the HVR-1 (Hexon variable region). This difference could also be observed between the isolates from different countries and continents.

\section{Conflicts of Interest}

The authors declare no conflicts of interest regarding the publication of this paper.

\section{References}

[1] Arsani, R.K., Gupta, B.K., Sharma, S.K., Singh, S.P. and Kotach, R.C. (1997) Hydropericardium Hydropathy Syndrome in Asian Poultry. The Veterinary Record, 141, 271-273. https://doi.org/10.1136/vr.141.11.271

[2] Ganesh, K., Suryanarayana, V.V.S. and Raghavan, R. (2002) Detection of Fowl Adenovirus Associated with Hydropericardium Hepatitis Syndrome by a Polymerase Chain Reaction. Veterinary Research Communications, 26, 73-80. https://doi.org/10.1023/A:1013361906791

[3] Zsak, L. and Kisary, J. (1984) Characterization of Adenoviruses Isolated from Geese. Avian Pathology, 13, 253-264. https://doi.org/10.1080/03079458408418529

[4] Hess, M. (2000) Detection and Differentiation of Avian Adenoviruses: A Review. Avian Pathology, 29, 195-206. https://doi.org/10.1080/03079450050045440

[5] Hess, M., Cuzange, A., Ruigrok, R.W., Chroboczek, J. and Jacrot, B. (1995) The Avian Adenovirus Penton: Two Fibres and One Base. Journal of Molecular Biology, 252, 379-385. https://doi.org/10.1006/jmbi.1995.0504

[6] Ojkic, D. and Nagy, E. (2000) The Complete Nucleotide Sequence of Fowl Adenovirus Type 8. Journal of General Virology, 81, 1833-1837.

https://doi.org/10.1099/0022-1317-81-7-1833

[7] Mansoor, M.K., Hussain, I., Arshad, M. and Muhammad, G. (2011) Preparation and Evaluation of Chicken Embryo-Adapted Fowl Adenovirus Serotype 4 Vaccine in Broiler Chickens. Tropical Animal Health and Production, 43, 331-338. https://doi.org/10.1007/s11250-010-9694-Z

[8] Zhao, J., Zhong, Q., Zhao, Y., Hu, Y.X. and Zhang, G.Z. (2015) Pathogenicity and Complete Genome Characterization of Fowl Adenoviruses Isolated from Chickens Associated with Inclusion Body Hepatitis and Hydropericardium Syndrome in China. PLoS One, 10, e0133073. https://doi.org/10.1371/journal.pone.0133073

[9] Shah, M.S., Ashraf, A., Khan, M.I., Rahman, M., Habib, M. and Qureshi, M. (2016) Molecular Cloning, Expression, and Characterization of $100 \mathrm{~K}$ Gene of Fowl Adenovirus-4 for Prevention and Control of Hydropericardium Syndrome. Biologicals, 44, 19-23. https://doi.org/10.1016/j.biologicals.2015.10.002

[10] Kish, L. (1965) Survey Sampling. John Wiley and Sons, Inc., New York.

[11] Shahzad, R., Jabbar, B., Naseer, N., et al. (2016) Serotype Characterization of Pakis- 
tani Aviadenovirus Strains Causing Inclusion Body Hepatitis and Hydropericardium Syndrome. Asian Journal of Applied Sciences, 4, 1095-1101.

[12] Huerta-Cepas, J., Serra, F. and Bork, P. (2016) ETE 3: Reconstruction, Analysis, and Visualization of Phylogenomic Data. Molecular Biology and Evolution, 33, 1635-1638. https://doi.org/10.1093/molbev/msw046

[13] Katoh, K. and Standley, D.M. (2013) MAFFT Multiple Sequence Alignment Software Version 7: Improvements in Performance and Usability. Molecular Biology and Evolution, 30, 772-780. https://doi.org/10.1093/molbev/mst010

[14] Niczyporuk, J.S. (2016) Phylogenetic and Geographic Analysis of Fowl Adenovirus field Strains Isolated from Poultry in Poland. Archives of Virology, 161, 33-42. https://doi.org/10.1007/s00705-015-2635-4

[15] De Herdt, P., Ducatelle, R., Lepoudre, C., Charlier, G. and Nauwynck, H. (1995) An Epidemic of Fatal Hepatic Necrosis of Viral Origin in Racing Pigeons (Columba livia). Avian Pathology, 24, 475-483. https://doi.org/10.1080/03079459508419087

[16] Domanska-Blicharz, K., Tomczyk, G., Smietanka, K., Kozaczynski, W. and Minta, Z. (2011) Molecular Characterization of Fowl Adenoviruses Isolated from Chickens with Gizzard Erosions. Poultry Science, 90, 983-989. https://doi.org/10.3382/ps.2010-01214

[17] Günes, A., Marek, A., Grafl, B., Berger, E. and Hess, M. (2012) Real-Time PCR Assay for Universal Detection and Quantitation of All Five Species of Fowl Adenoviruses (FAdV-A to FAdV-E). Journal of Virology Methods, 183, 147-153. https://doi.org/10.1016/j.jviromet.2012.04.005

[18] Kajan, G.L., Kecskemeti, S., Harrach, B. and Benko, M. (2013) Molecular Typing of Fowl Adenoviruses, Isolated in Hungary Recently, Reveals High Diversity. Veterinary Microbiology, 167, 357-363. https://doi.org/10.1016/j.vetmic.2013.09.025

[19] Pichla-Gollon, S.L., Drinker, M., Zhou, X., Xue, F., Rux, J.J., Gao, G.P., Wilson, J.M., Ertl, H.C., Burnett, R.M. and Bergelson, J.M. (2007) Structure-Based Identification of a Major Neutralizing Site in an Adenovirus Hexon. Journal of Virology, 81, 1680-1689. https://doi.org/10.1128/JVI.02023-06

[20] Yu, B., Wag, C., Dong, J., Zhang, M., Zhang, H., Wu, J., Wu, Y., Kong, W. and Yu, X. (2012) Chimeric hexon HVRs Protein Reflects Partial Function of Adenovirus. Biochemistry Biophys Research Communication, 421, 170-176. https://doi.org/10.1016/j.bbrc.2012.03.125

[21] Toro, H., Gonzalez, O., Escobar, C., Cerda, L., Morales M. and Gonzalez, C. (2001) Vertical Induction of the Inclusion Body Hepatitis/Hydro-Pericardium Syndrome with Fowl Adenovirus and Chicken Anemia Virus. Avian Diseases, 45, 215-222. https://doi.org/10.2307/1593031 